\title{
Safety assessment of moso bamboo column under fire by using bamboo as protection layer
}

\author{
Laila Fitriana ${ }^{\mathrm{a}^{*}}$, Mengting Tsai ${ }^{\mathrm{b}}$ \\ ${ }^{a}$ Freelancer researcher, Tulungagung, East Java 66291, Indonesia \\ ${ }^{b}$ National Taipei University of Technology, No.1, Sec. 3, Zhongxiao E. Rd., Taipei 10608, Taiwan \\ *Corresponding author. Tel.: +6281330413193 \\ E-mail address: lailafit0105@gmail.com
}

\begin{abstract}
Global warming issue has forced the construction world including architecture to find the green material in order to minimize $\mathrm{CO}_{2}$ which damages to the nature. In the beginning, wood was one of the green material but it has long growth cycle. Lately, bamboo has been chosen for its fast growing cycle and resuming some wood properties, also known as local material and eco-friendly benign to the nature. Generally, wood and bamboo are composed by carbon-based compound. So, they are combustible and flammable when they are exposed to the fire. Up to now, there are not so many studies regarding the fire behavior of raw round bamboo which is used as the structure. To investigate the effectiveness of bamboo protection layer, the nine-trunk bamboos will be tied up to construct the column. A one bamboo will be placed in the middle and surrounded by the other eight-bamboos -as the protection layer of the center. All of them are with no-fire retardant. By doing this, it is possible to obtain knowledge upon bamboo on its natural properties. Specimen will be exposed to the fire inside the furnace up to $700^{\circ} \mathrm{C}$. The temperature changing on the specimen will be measured by thermocouples which are installed inside and outside the wall of main bamboo in the center part. The main bamboo is expected to have lower temperature than its auto-ignition temperature, so that the structure will be able stand out during the fire until the occupants able to be evacuated safely.
\end{abstract}

Keywords: Auto-ignition temperature; bamboo physical properties; green materials; flammable; Moso bamboo

\section{Introduction}

Bamboo has been known for thousands of year by ancient Asian and Indian people. Ancient of Chinese people used it as the material to make 'fire arrows'. In India, bamboo also was familiar with the local people. It was often used because of its possibility to afford and easy to find. For some decades, this giant grass was portraying the image of the poor. Later on the researchers have been investigating the properties of engineered bamboo. In Asia itself, some usage of bamboo are on its original raw round material. It is the green material with sustainability, environmental friendliness, also able to be reused and recycled. (Li, Zhang, Huang, \& Deeks, 2013).

This material can be used as the structural part of the building to construct and to support the building stay stand whether as the column, beam, or another type of construction elements. Such as in Asia, some architecture buildings intend to use bamboo in original shape to construct such long-span building and even some arches form. The fact shows that is possible for bamboo to grow up to 35 inches within 24 hours period of time. Another benefit is producing oxygen $\left(\mathrm{O}_{2}\right)$ during its growing period, and sequestrating the carbon dioxide $\left(\mathrm{CO}_{2}\right)$ in the nature (INBAR, 2015). Some well-known architects in Asia -Kengo Kuma, Shigeru Ban, and Vu Truong Nghia have been re-introduced bamboo with the new-outlook in the new forms and possibilities to apply. 
There are several factors that need to be concerned for using some material such as fire safety, durability, sustainability (environmental impact), user safety, and energy efficiency. Fire safety is important issue in some flammable material such as wood and bamboo as well. Both bamboo and wood are composed by the carbon based compound. Since bamboo is sustainable yet the fire behavior still remains unknown. This study attempt to understand the fire behavior upon the bamboo by conduct the real testing of several part of the structure constructed from bamboo.

In this research the specimen intentionally with either fire retardant or fire chemical compound. So the material will be keep maintained as its original from the nature. This can able to explore more the properties of bamboo on its natural stage.

\section{Research theory and methods}

Yan et al. (2012) had carried out the experiment to investigate the fire behavior upon the glubam (glue laminated bamboo) -which were constructed from the bamboo strips in full scale model. After 1 hour of fire burning, it showed that the laminated bamboo frame building was able to sustain. The $10 \mathrm{~mm}$ thick of gypsum board also played an important factor in order to make the structural resist to the fire with temperature that almost reached up $700{ }^{\circ} \mathrm{C}$. After 12 hours of investigation, the spread of the fire was identified only localized in some parts that indicate glubam elements have good fire resistance. Full scale model is being tested using the glubam grids system. It used beams as frame system. As the result of the experiment, the glubam model room sustained more than one hour of fire that generated by the wood cribs. As the result, the part with glubam protection, the wall and the ceiling, were recorded have $686{ }^{\circ} \mathrm{C}$ for interior, $48{ }^{\circ} \mathrm{C}$ and $84{ }^{\circ} \mathrm{C}$ for exterior respectively. It was effectively reduce the raising temperature that caused by fire.

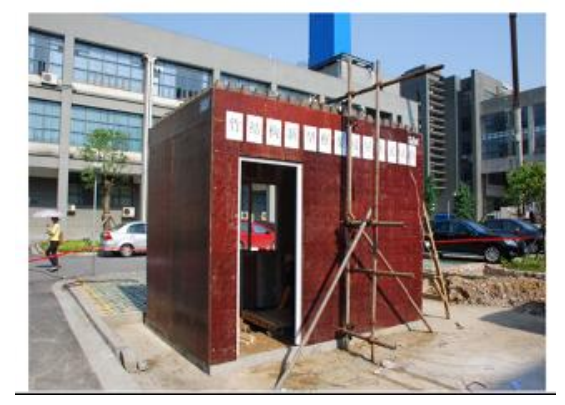

Fig. 1. Bamboo fire behavior testing (Yan et al. 2012)

Another study on bamboo behavior that had been conducted in the previous research (Liu, Tsai, \& Fitriana, 2016) the fire testing upon the bamboo to investigate its compression capacity on Moso Bamboo. This research upon the non-fire proofed bamboo showed that bamboo still worked well under 10 minutes burning after performed some compressive testing. Also for 15 minutes burning, the compressive testing showed proper numeral result yet physically some of specimen was producing charcoals and broken.

One specimen is constructed by nine trunk bamboos which are joined by the stainless steel wire. In some method to protect wood column as the structure, it will be protected by some additional material which is working as the sacrificial layer. Yet in this research, the bamboo is used to protect the bamboo itself. This arrangement will let one bamboo becomes the main structure with the 8-other become the sacrificial layer. Then this part will be keep able to retain the structural capacity as the uncharred area. Unlike the non-charred area, the charred area will be weak and does not have the structural capacity. 
a.

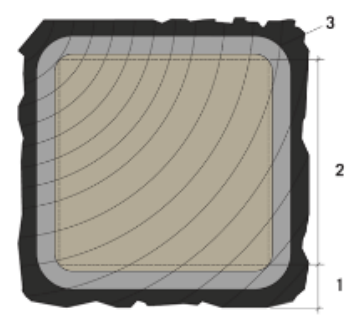

b.

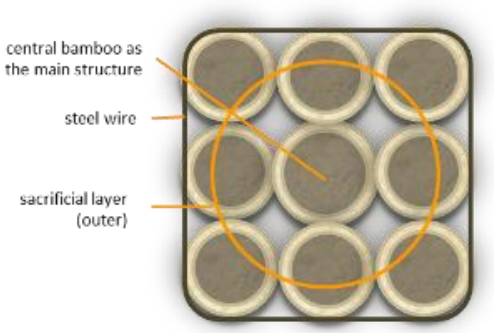

Fig.2. (a) Wood Sacrificial Layer (The Case for Tall Wood Buildings,p.113) (b) Bamboo Protection Layer

\section{Wood Charring Structural Design Diagram}

1 Sacrificial layer (char layer and pyrolysis zone; no structural capacity)

2 Residual sections (structural capacity retained)

3 Rounded corner (The Case for Tall Wood Buildings; p. 113)

It is commonly happening in heavy timber members, even the wood as structural part of the building has been damaged by fire, it still able to sustain the structural capacity in the non-charred area. To protect the structural part of the timber as non-charred area, some additional layer added to act as sacrificial one (The Case for Tall Wood Buildings (mgb ARCHITECTURE + DESIGN, Equilibrium Consulting, LMDG Ltd, \& BTY Group, 2012)). In the figure above, there are several layers may be produced of wood when it is facing to the fire. This sacrificed layer is the part where the charcoal is produced and it has no structural capacity to bear the load but it can protect the inside.

\subsection{Bamboo Specimen}

Based on those ideas, this research will be conducted to study the possibility of sacrificed layer in bamboo to protect the main structure yet the bamboo itself will be used as the sacrificial layer. Thermocouples will be installed inside the main bamboo and outside its wall for recording the temperature changing during the fire. Specimen of this research, the Moso Bamboo (Phyllostachys edulis) was sourced locally from Taiwan, which is also can be found in Japan, Korea, China and some part of Vietnam. This research investigates the fire behavior of round Moso Bamboo with range diameter around 4-6 cm with the wall thickness varies from 0,5 up to 0,8 cm. Moso Bamboo is part of Genus Phyllostachys, species Phyllostachys edulis. For this research, the specimen will be $30 \mathrm{~cm}$ in length. Nodes are excluded to get the real result on its optimal behavior of bamboo strength. Every specimen used the internodes bamboo. Internodes are part of bamboo which is located between the nodes. Moreover, the node is much stronger and harder than other part in the same bamboo stalk.

a.

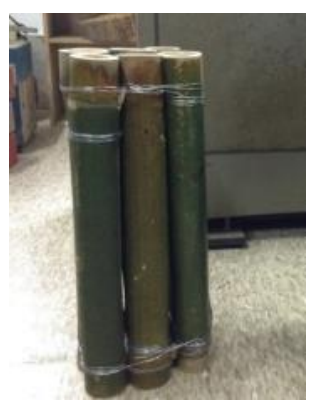

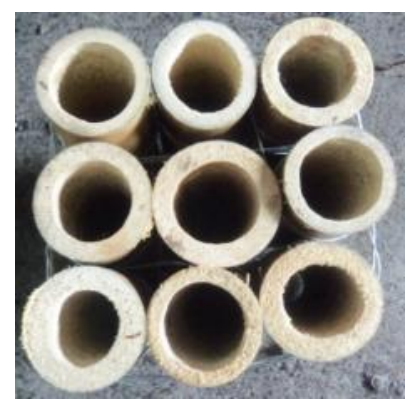

Fig. 3. (a) Bamboo specimen from side (b) Bamboo specimen from top view 


\subsection{Auto-ignition temperature}

Auto-ignition for bamboo is quite similar to the wood. Bamboo has almost the same peak temperature whether it can be burnt by itself at $204.4^{\circ} \mathrm{C}$. Time gaps are chosen based on the report from the bamboo-made building in Indonesia, the Green School. For safely evacuate all occupants from the building, it needs 13.41 minutes. This can be used as the limit for the first study of raw round bamboo under the fire. For the comparison, the pine tree and oak have $219^{\circ} \mathrm{C}$ and $250{ }^{\circ} \mathrm{C}$ for the auto-ignition temperature.

Furnace as the place where the experiment will be carried out, it has some temperature changing along with the time of burning. The relationship between the temperature and the time will be drawn by the numerical equation below:

$$
\begin{array}{ll}
\mathbf{T}=20+345 \times \log _{10}(8 \mathrm{t}+1) & \text { In which: } \\
& \mathrm{T}=\text { temperature }\left({ }^{\circ} \mathrm{C}\right) \\
& \mathrm{t}=\text { time }(\mathrm{s})
\end{array}
$$

From that equation, by substitute' $t$ ' variable, it will be clearly drawn the temperature curve as it in Fig. 4 below. Temperature has slightly changed from the minute 0 to the 120 . After 150 minutes, the changing is not that huge.

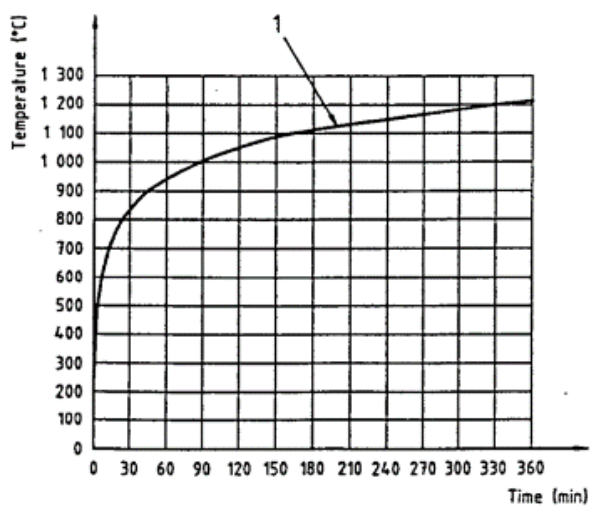

Fig. 4. Furnace Temperature ISO 834-1

\subsection{Experimental Section}

Fire was set up with the maximum temperature at $700{ }^{\circ} \mathrm{C}$. The fire testing was carried out in accordance with ISO 834-1. Those un-engineered bamboos were burnt with 5, 10, and 15 minutes for each. Furnace has several holes inside to spray out the fire into the specimen that produced by the burner on two sides.

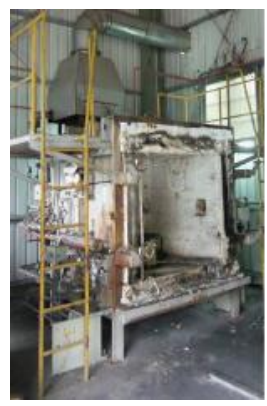

b.

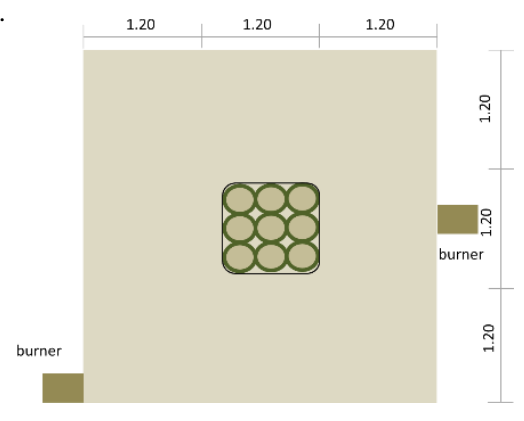

Fig. 5. (a) Furnace (b) furnace plan and specimen inside. 

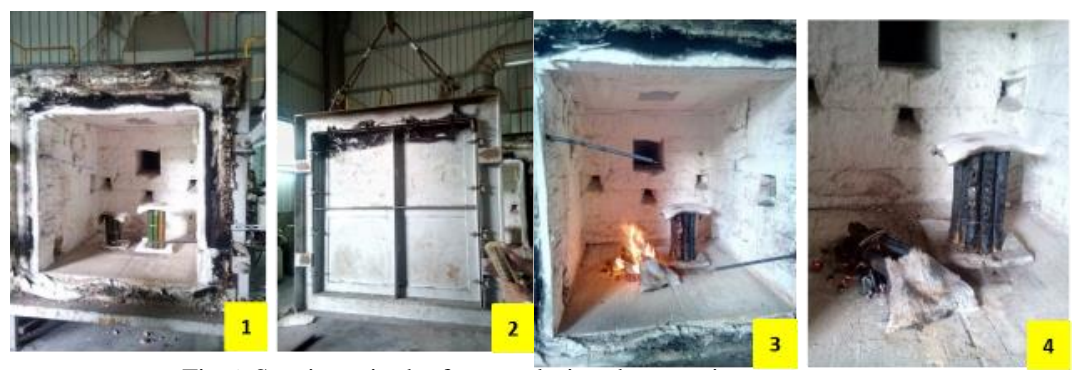

Fig.6. Specimen in the furnace during the experiment process

Specimens were put inside the furnace and close it properly before the fire started (Fig. 6.1 and 6.2). Right after the time had been approached for each testing, the furnace will be opened to observe the result as it showed in fig. 6.3. In some case, there will be some fire still remains. After the fire stopped, the specimen will be easier to observe.

\section{Results and Discussions}

Based on the result from experimental process that had been conducted previously, the fire testing result showed mostly the temperature of the inside and outside of main column are below the auto-ignition point.

\subsection{5 minutes burning result}

The results of the testing -after the fire stopped for the specimen on 5 minutes burning are presented in the figures below. Each side of the specimen has no damage and no char found.

Curve on Fig.8. was showing that there is big difference between the environment's temperature and the central column, either the inside of the central column or the outside part of the central column. By the changing temperature on the curve, the environment's temperature indicates the dramatic changing for the first 2-3 minutes. Later, the temperature is changing slightly.

a.

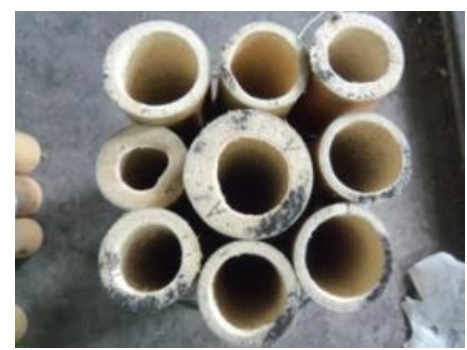

b.

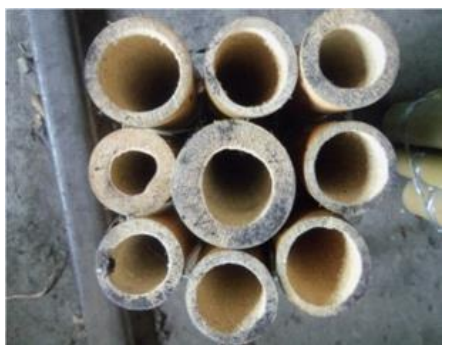

c.

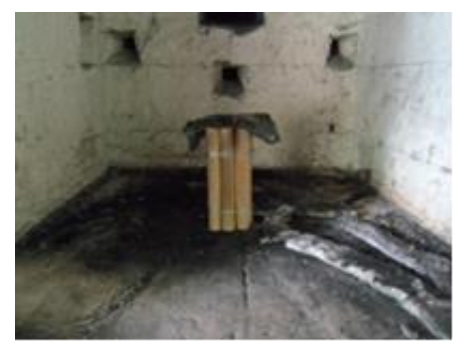

Fig.7. Specimen (a) before 5 minutes burning, (b) after, (c) specimen in the burner after the fire

From the experiment, the environment temperature inside the furnace reaches up to $581{ }^{\circ} \mathrm{C}$, based on the calculation. In the beginning, the inside and outside of main bamboo didn't have the big difference temperature. By the time passes, then the environment temperature increases, it started to have some temperature gaps since the 2 minutes. The outside temperature is increasing gradually. But the inside keeps remain and stable between $27-28{ }^{\circ} \mathrm{C}$ when the outside already recorded at $30^{\circ} \mathrm{C}$. As recorded by the thermocouple, the inside of main bamboo (central bamboo) reaches $48^{\circ} \mathrm{C}$ with the outside of the main column reaches $78^{\circ} \mathrm{C}$. In the end of the fire testing, the temperature from the inside and the outside has $40{ }^{\circ} \mathrm{C}$, it is about $38.46 \%$ difference. 


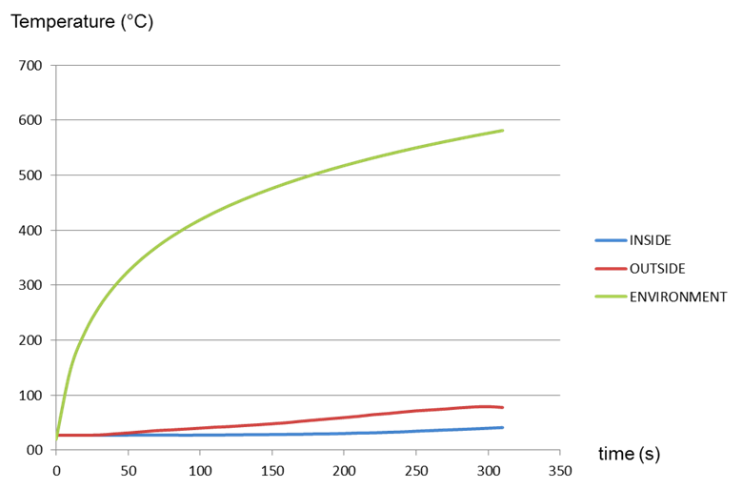

Fig. 8. Temperature for inside, outside and environment of 5 minutes burning

The figure above showed there is gap between temperature inside and outside started from the 100th second. Within 300 seconds (5 minutes) the gap becomes bigger. Both the inside and outside temperature are below $100{ }^{\circ} \mathrm{C}$ and it is still much lower than the auto-ignition peak.

\subsection{0 minutes burning result}

At the 10 minutes burning specimen, there are some charcoals produced in the outer area. The main part of the structure, which is the central bamboo -there is no damage on it. Yet the charcoals are produced surrounding it. Charring can be happened as the result of the decomposition of macro-chemically process within the bamboo itself, because the charcoals will be determined in such area which is exposed directly to the fire. It indicates that after 5 minutes burning until 10 minutes, the charring has started appear quite evenly happened surround the main bamboo.

a.

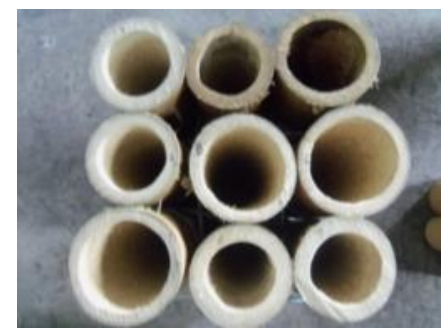

b.

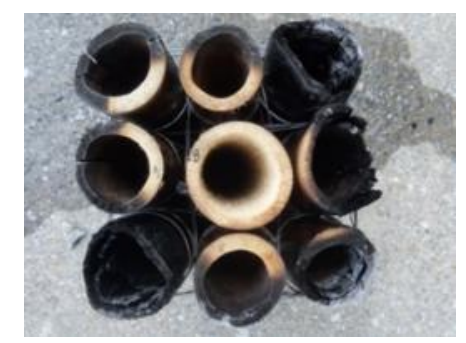

Fig.9. Specimen (a) before the burning for 10 minutes, (b) after the fire

In the beginning, the inside temperature and the outside are started at the equal state. After the fire runs for 1.5 minutes, the outside temperature started to increase. As the environment temperature increases, the outside temperature changes gradually. If we compare the curve between the 5 minutes burning and 10 minutes burning, there will be some similarities. At the 5th minutes burning, the gaps between inside and outside temperature can be seen clearly. The gap has been recorded at the period 5th and 6th minutes between the inside and the outside are about 20 ${ }^{\circ} \mathrm{C}$.

Right after it runs for 6 minutes, the gaps temperature between the inside and outside of the central bamboo become smaller until it reaches the gaps that can be recorded in to the stable number. It means that the temperature inside and outside are in balance situation due to the changing of the physical properties. Charcoal has been produced. Fig. 10 after the fire stopped. From the left figure, there are some charcoals produced while the specimen keeps smoldering. It causes more damage and burn the area surround. The outer part of the specimen has produced the 
charcoal. As it can be seen from the figure above, charcoal covers almost the whole surface of specimen that faced the fire through the experiment. Therefore, the existence of charcoal will be physically changed bamboo into more easily being rupture and cracking.

a.

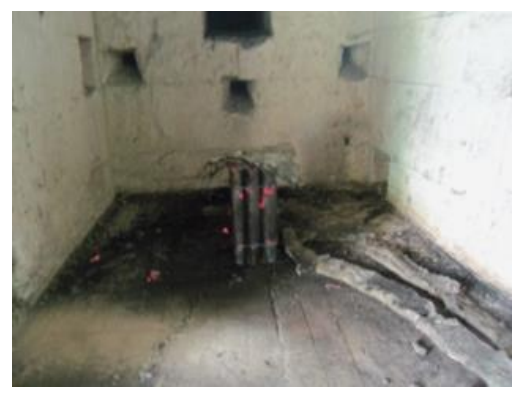

b.

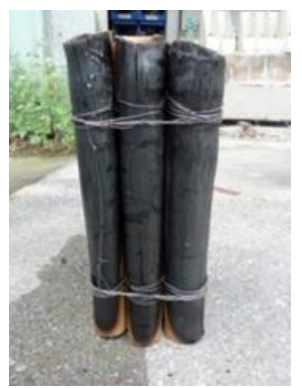

Fig.10. Specimen after the fire (a) inside the furnace, (b) out from the furnace

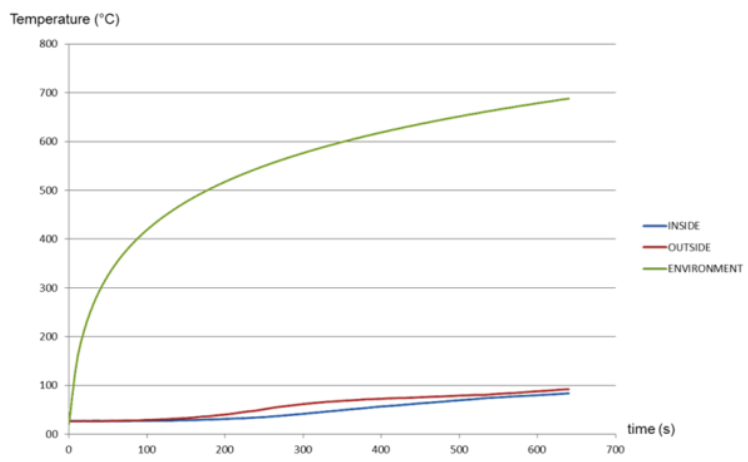

Fig. 11. Temperature for inside, outside and environment of 10 minutes burning

\subsection{5 minutes burning result}

The majority of specimen produced the charcoal and caused damage especially the outer layer of bamboo. After charcoal has been produced on the bamboo surrounding of the central bamboo, there are also some area loss. It affects the outer temperature, so that this part does not have the protection from the direct contact with the fire anymore. This is also can be described more using the curve and its trending line.

a.

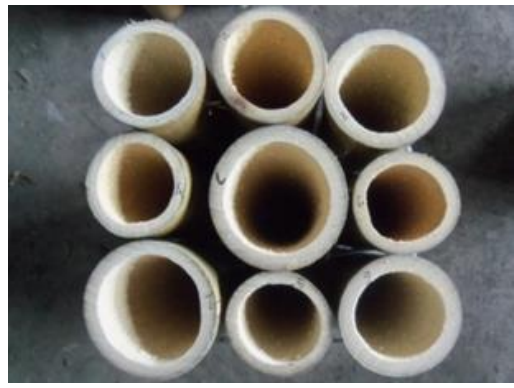

b.

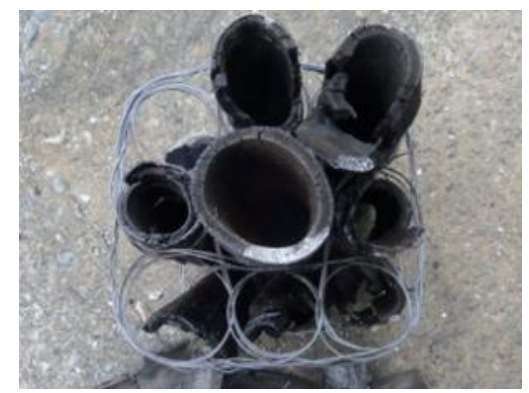


Fig.12. Specimen (a) before the fire (b) after 15 minutes burning

As recorded in the experiment, the difference temperature between the inside and the outside. The difference between inside and outside temperature can be described due to the changing phase of the bamboo properties, especially when the outside layer of bamboo has been changed into charcoal. In the first 5 minutes, as the time increases, the temperature gap between inside and outside of central bamboo reaches $22{ }^{\circ} \mathrm{C}$ (inside: $31{ }^{\circ} \mathrm{C}$ - outside: $\left.53{ }^{\circ} \mathrm{C}\right)$.

a.

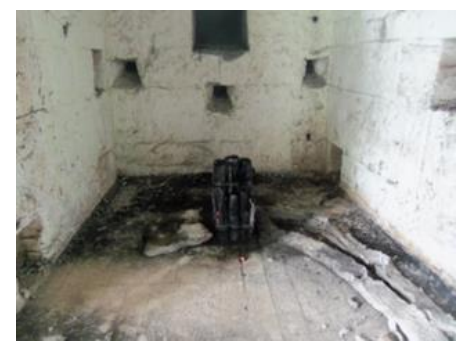

b.

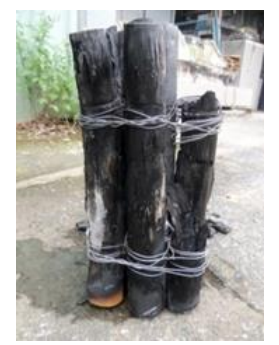

Fig.13. Specimen after the fire (a) inside the furnace, (b) out from the furnace

In this research, at the fifth minute, the inside of central column temperature and the outside have reached $45^{\circ} \mathrm{C}$ and $68{ }^{\circ} \mathrm{C}$ respectively. For comparison with the two first specimens, the first specimen that has the 5 minutes for burning, it reaches $40{ }^{\circ} \mathrm{C}$ and $79{ }^{\circ} \mathrm{C}$. In the other hand, the 10 minutes specimen has $45{ }^{\circ} \mathrm{C}$ and $65{ }^{\circ} \mathrm{C}$ at the first 5 minutes. These two specimens have quite the same temperature. Amongst these two others specimen, the temperature gap between inside and outside, the third specimen has quite similar with the second specimen temperature. Continuously for the temperature at the tenth minute for each inside and outside the central bamboo are recorded 78 ${ }^{\circ} \mathrm{C}$ and $127^{\circ} \mathrm{C}$. While the second specimen in which has the 10 minutes as the maximum time for burning, has $83{ }^{\circ} \mathrm{C}$ and $91{ }^{\circ} \mathrm{C}$.

In the end of the test, as it can be seen from the figures above, almost whole parts of surround central bamboo have produced charcoal. Even for the central bamboo, due to the loss area for outside layer bamboo, the fire finally reached the central bamboo. This also initiates the central bamboo to produce charcoal as well.

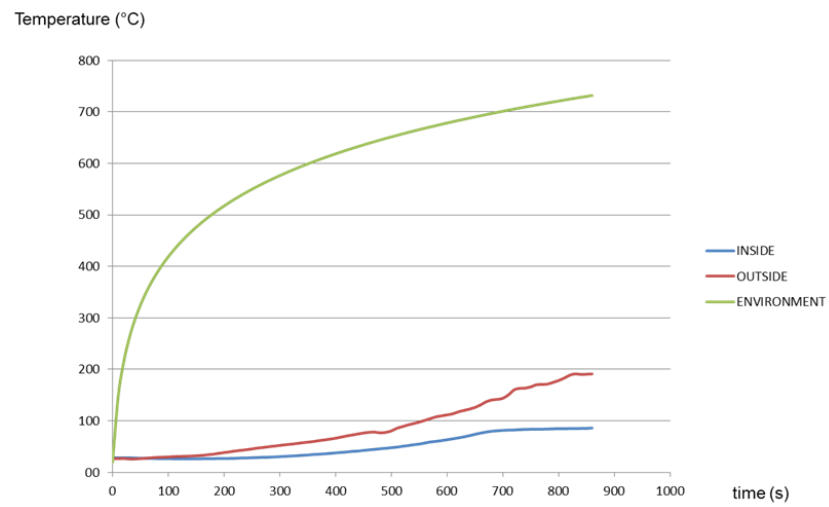

Fig.14. Temperature for inside, outside and environment of 15 minutes burning

From the curve above, the outside temperature almost reached up $200{ }^{\circ} \mathrm{C}$ where the auto-ignition temperature of bamboo is $204.4^{\circ} \mathrm{C}$. It also has 


\subsection{Combined result}

This curve shows the comparison amongst temperature of those three specimens. Inside 5 represents the 5 minutes burning of the inside central bamboo temperature, also for inside 10 and inside 15 represent the 10 and 15 minutes temperature of inside the central bamboo as well. The 5 and 10 minutes curves have similarities in shape. Starting points are around $27^{\circ} \mathrm{C}$. So it does for the 15 minutes burning. As it can be seen from the curve when the time reaches 3 minutes, the temperature increases rapidly until the end of 10 minutes burning up to $92{ }^{\circ} \mathrm{C}$ (for the 10 minutes burning). Yet for the 15 minutes burning, the temperature increase 1 minute later than the two other specimens. Still, this also has the same curve with two previous experiments.

As can be seen from the curve below, technically the three curves have their own characteristics. For the 5minutes and 10-minutes burning, they have the similarities in trending line. Yet the 10-minutes has approximately 1 minute later than 5-minutes curve to rise the temperature dramatically. At this curve, there is overlapping point when both the 10-minutes curve and 15-minutes curve at the 7th minutes. Compared to the two others specimen, the third specimen has the serious damage upon its outer bamboo row.

a.

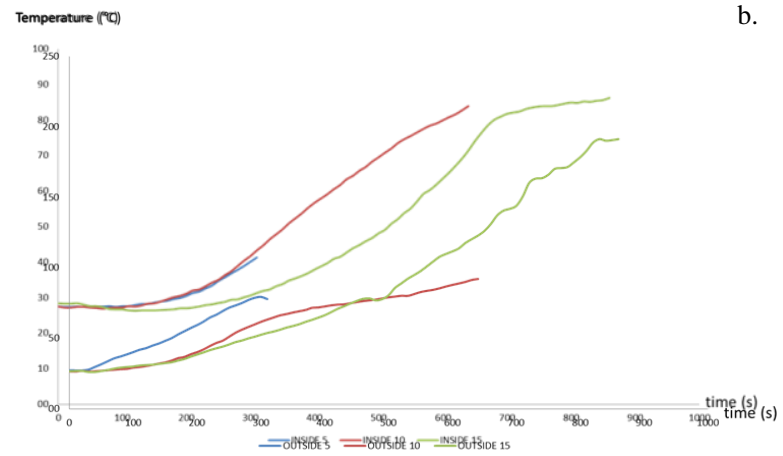

Fig,15. Comparison amongst all three time gaps, inside the central column (a), outside (b)

The 10 and 15 minutes burning curves showed the similar trending line both for outside and inside temperature. But for 15 minutes temperature, it has different behavior with two previous time gaps due to its physical changing.

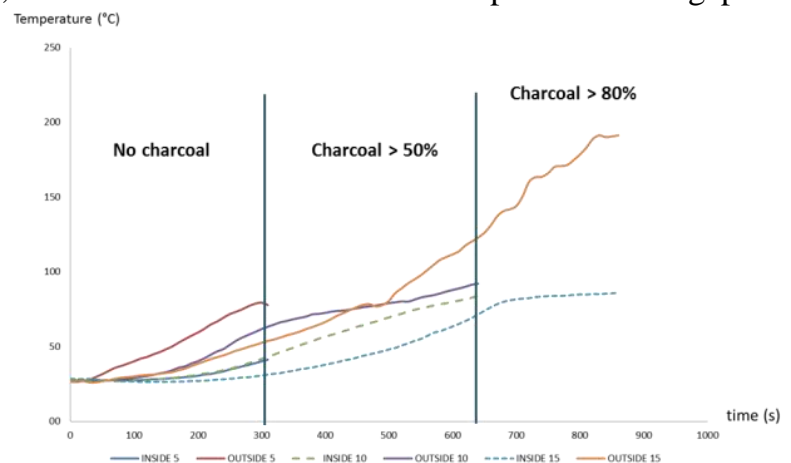

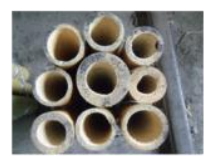

$5 \mathrm{~min}$

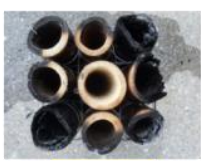

$10 \mathrm{~min}$

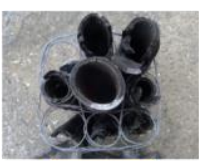

$15 \mathrm{~min}$

Fig.16. Comparison amongst all three time gaps 


\section{Conclusions}

a. Based on the result of this experiment, the arrangement of 9 Moso bamboo trunks as the column and specimen as well, can effectively obstruct the fire to burn the central bamboo. This can be working on 5 minutes and 10 minutes burning. Laboratory test shown that when the bamboo had been burnt for 15 minutes burning, the charcoal already produced in overwhelm ratio. The majority area is loss. So that, there is no protection for the central bamboo after.

b. Different time gaps give the clearly different stage of physical changing in bamboo. At the 5 minutes burning, the bamboo almost still in perfect condition. There is no difference between the 5 minutes burning and the initial specimen. For additional 10 minutes burning, it gets the half of outer area which surrounds the main column got burnt. The longest period, the 15 minutes burning, it shows that the majority of bamboo specimen already produces charcoal.

\section{Future research}

More studies on bamboo are needed in order to investigate its fire properties and behavior. For comparison, it can be used another type of bamboo with different sizes and arrangement to obtain the optimal possibility of bamboo fire properties. Since the research had been done in Taiwan, the bamboo was sourced locally from that region. For another region such as Indonesia, with different types of bamboo species availability, it is suggested to use the local species as the specimen.

\section{Acknowledgment}

The research described in this paper was supported by Department of Architecture and Civil Engineering of National Taiwan University of Science and Technology for the tools, materials and equipment. The author also greatly appreciates the contribution by Department of Architecture of National Taipei University of Technology.

\section{References}

Li, H., Zhang, Q., Huang, D., \& Deeks, A. J. (2013). Compressive performance of laminated bamboo. Composites Part B: Engineering, 54, 319328. https://doi.org/10.1016/j.compositesb.2013.05.035

Liu, W.-T., Tsai, M.-T., \& Fitriana, L. (2016). Experimental Study on Residual Compressive Strength of Bamboo Column under Fire With Different Time Limitation. In World Conference on Timber Engineering. Vienna.

mgb ARCHITECTURE + DESIGN, Equilibrium Consulting, LMDG Ltd, \& BTY Group. (2012). THE CASE FOR Tall Wood BUILDINGS How Mass Timber Offers a Safe, Economical, and Environmentally Friendly Alternative for Tall Building Structures. 